\section{THE EFFECT OF 'TELEMEDICINE' ON GLYCAEMIC CONTROL AND OTHER CLINICAL OUTCOMES IN CHILDREN AND ADOLESCENTS WITH TYPE 1 DIABETES - A SYSTEMATIC REVIEW AND METAANALYSIS OF RANDOMISED CONTROLLED TRIALS}

Moosakutty Chettiyarammel Thandu Parakkal ${ }^{*}$, Nithya Sukumar. Letterkenny University Hospital

\subsection{6/archdischild-2021-europaediatrics.210}

To systematically review the published randomised controlled trials (RCT) that evaluate the effectiveness of telemedicine (TM) in terms of glycaemic control primarily and other clinical outcomes such as quality of life, patient satisfaction and severe hypoglycaemic episodes in children and adolescents with type 1 diabetes.

Design: The randomised controlled trials are extracted from data sources including Medline/PubMed, EMBASE, Web of Science, PsycINFO, Cochrane Library and CINAHL using the PICO modelP Children and adolescents with Type 1 diabetes I Telemedicine (TM) C Conventional model healthcare O Primary Outcome: Glycaemic control as observed by glycosylated haemoglobin (HbA1c) Secondary Outcomes: Diabetes related quality of life (DQol), Patient satisfaction, Severe hypoglycaemic episodes The search identified 1199 records and 16 trials were eligible o The meta-analysis showed a marginal improvement in glycaemic control at three months follow up which did not reach statistical significance and was not sustained at six months follow up.

o Only few studies evaluated the effect on patient satisfaction, DQoL (Diabetes-related quality of life) and occurrence of severe hypoglycaemic episodes which also showed no significant difference between the intervention and control groups.

This study found limited evidence to support the use of TM in children and adolescents with type 1 Diabetes.

o However, it must be noted that this intervention did not result in an increase in significant adverse effects such as frequency of severe hypoglycaemic episodes or DKA.

o Our subgroup analysis indicated a small improvement in HbA1c at three months which was not sustained at six months follow up. This could be improved by using sustained re-inforcement strategies.

o This study is limited by high heterogeneity, limited evidence base on many of the outcomes and the use of various modes and intensities of telemedicine interventions making the evaluation of outcome efficacy and cost-effectiveness assessment difficult.

o High-quality RCTs are needed to evaluate the role of $\mathrm{TM}$ in improving glycaemic control in this patient population

\section{INADEQUATE SLEEP HABITS ARE ASSOCIATED WITH OBESITY IN HIGH SCHOOL CHILDREN}

Liubov Rychkova*, Irina Madaeva, Olga Berdina, Svetlana Bolshakova, Olga Bugun. Scientific Centre for Family Health and Human Reproduction Problems

\subsection{6/archdischild-2021-europaediatrics.211}

Objective to examine sleep habits and associations between inadequate sleep habits and measures of obesity in high school adolescents.

Methods A total of 127 adolescents (61\% male) aged 15-17 years were recruited from patients of the Children's hospital referred to due to obesity and other conditions in 2017-2019 years. The sample was evaluated to determine if a relationship existed between inadequate sleep habits and measures of obesity (percentile weight-for-length - body mass index - BMI, $\mathrm{kg} / \mathrm{m} 2$; neck circumference - NC, $\mathrm{cm}$; waist circumference WC, $\mathrm{cm})$.

Participants provided demographic information and completed the Adolescent Sleep Habits Survey (ASHS). Adolescent weight/length, NC and WC were measured; obesity defined as $\mathrm{BMI} \geq 95$ th percentile, $\mathrm{NC} \geq 90$ th percentile and $\mathrm{WC} \geq 90$ th percentile for age and sex. Measures of inadequate sleep habits: possible activities in bed and possible activities if difficulty falling asleep in the last two weeks. All associations were analyzed using a method of odds ratios (ORs) with 95\% confidence intervals [CIs]. All differences were considered significant at $\mathrm{p}<0.05$.

Results A greater proportion of males than females $(52.6 \%$ versus $43.7 \%$, p <

0.05 ) and of obese adolescents compared with lean peers $(64.2 \%$ versus $39.1 \%, \mathrm{p}<0.05)$ reported inadequate sleep habits. Sleep habits named «ASHS activity in bed» such as «Eat every night» was associated with BMI $\geq 95$ th percentile (OR 1.30, 95\% CI 1.25-1.35), NC $\geq 90$ th percentile (OR 1.65, 95\% CI 1.59-1.71) and WC $\geq 90$ th percentile (OR $1.72,95 \%$ CI 1.65-1.88). Possible activities if difficulty falling asleep such as «Wake up and to do something (e.g., eat; drink warm milk/coffee) every night» were also associated with measures of obesity: BMI $\geq 95$ th percentile (OR 1.35, 95\% CI 1.29-1.41 and OR 1.21, 95\% CI 1.17-1.25, respectively), NC $\geq 90$ th percentile (OR 2.10, 95\% CI 1.8-2.65 and OR 1.75, $95 \%$ CI 1.59-1.91, respectively) and WC $\geq 90$ th percentile (OR 2.5, 95\% CI 1.89-3.1 and OR 2.2, 95\% CI 1.28-2.99, respectively). Inadequate sleep habit such as «Watch TV in bed every night» was found to be associated with measures of obesity after adjusting for several covariates. No statistical significance was found if the above measures of inadequate sleep habits were noted as «twice or once in the last two weeks» in relation to $\mathrm{BMI}, \mathrm{NC}$ or WC.

Conclusion In addition to existing literature, this study found that inadequate sleep habits every night as well as short sleep duration in late adolescence may relate to the development of obesity as measured by BMI, NC, and WC.

\section{VITAMIN D INSUFFICIENCY AND CARDIO METABOLIC CONSEQUENCES IN CHILDREN WITH OVERWEIGHT OBESITY}

Alije Keka Sylaja* ${ }^{*}$ Atifete Ramosaj-Moina, Arbana Baloku-Zejnullahu, Vjosa Mulliqi-Kotori, Daniela Miladinova. Pediatric Clinic, University Clinical Center of Kosovo, Prishtina, 10000 Kosovo

\subsection{6/archdischild-2021-europaediatrics.212}

Obesity, vitamin D deficiency and cardio-metabolic consequences represent some of the most important widespread health concerns worldwide. There is a well-established inverse relationship between vitamin D status and obesity shown in a few observational studies. There are no comprehensive data on vitamin D deficiency among children with obesity in Kosovo. The aim of the study was to assess the prevalence of vitamin D deficiency and metabolic disorders among children with obesity and overweight. 